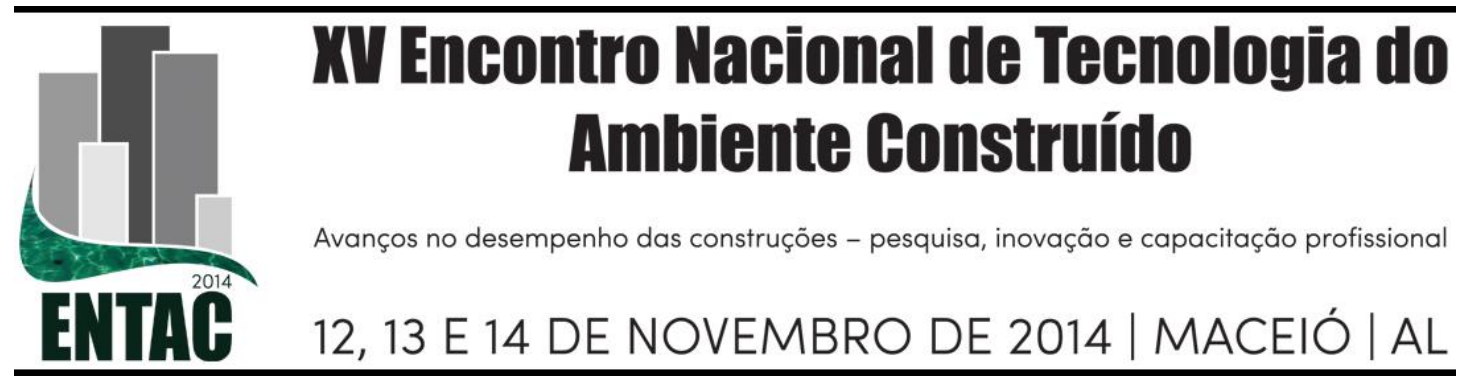

\title{
MONITORAMENTO TÉRMICO DA BIBLIOTECA NILO PEÇANHA LOCALIZADA EM JOÃO PESSOA/ PB
}

\author{
AMORIM, Rafael Ponce de Leon (1); PEDROSA, Maria Luiza (2); CARVALHO, \\ Homero Jorge Matos (3) \\ (1) IFPB, e-mail: rafael.ponce@ifpb.edu.br (2) IFPB, e-mail: pedrosamarialuiza@hotmail.com, (3) IFPB, \\ e-mail: homerojmc@gmail.com
}

\begin{abstract}
RESUMO
A busca por eficiência energética nas edificações é uma importante estratégia para redução da demanda de energia nas cidades. Neste sentido, diversos estudos estão sendo realizados visando à redução do consumo energético nas edificações sem, contudo, reduzir a capacidade de promover conforto aos seus usuários, nem reduzir a produção. Como resultado observa-se a concepção de novos projetos mais eficientes e a adequação de edifícios já existentes, também conhecida por "retrofit". Este artigo apresenta os resultados da avaliação de desempenho térmico do edifício da biblioteca Nilo Peçanha localizada em João Pessoa/ PB, buscando verificar a eficiência de sua envoltória e as consequências para o conforto térmico de seus usuários. Trata-se de uma pesquisa experimental e explicativa, realizada como uma das etapas do projeto PIBICT - Programa Institucional de Pesquisa Científica e Tecnológica, realizada pelo Laboratório de Conforto do Ambiente do Curso Superior de Tecnologia de Design de Interiores do Instituto Federal de Educação, Ciência e Tecnologia da Paraíba, Campus João Pessoa. A pesquisa partiu do monitoramento da temperatura e da umidade relativa do ar no interior e no exterior da edificação durante trinta dias consecutivos de verão. O monitoramento foi feito utilizando-se no exterior uma estação meteorológica La Crosse e um termohigrômetro com datalogger, marca ONSET, modelo HOBO U10. No interior o monitoramento foi feito com outros 19 termohigrômetros, posicionados em diversos ambientes da biblioteca. Os dados medidos foram tratados no software Microsoft Excel 2010 e espacializados nas plantas baixa da biblioteca. Foi constatado o baixo desempenho térmico da edificação, proporcionado, principalmente pelo baixo desempenho da cobertura, composta por telhas de fibrocimento e forro de gesso, e das fachadas leste e oeste, onde se encontram grande janelas em vidro, sem proteção contra a radiação solar.
\end{abstract}

Palavras-chave: Desempenho Térmico, Conforto Térmico, Envoltória.

\begin{abstract}
The search for energy efficiency in buildings is an important strategy for the reduction of energy demanding in cities. Because of that, several studies have being conducted in order to reduce energy consumption in buildings, without reducing neither the capacity of providing comfort to its users, nor reducing the production. As a result, it is observed
\end{abstract}


the conception of new and more efficient projects and the adequacy of existing buildings, also known as "retrofit". This paper presents the results of the evaluation of thermal performance of the bulding of Nilo Peçanha Library, in João Pessoa/PB, aiming at verifying the efficiency of its envelope and the consequences for its users' thermal comfort. It is an experimental explanatory research, conducted as one of the steps of PIBICT - Institutional Program of Technological and Scientific Research, a project conducted by the Environment Comfort Laboratory of Undergraduate Course of Technology in Interior Design of Federal Institute of Education, Science and Technology of Paraíba, campus João Pessoa. The research started from the monitoring of temperature and air relative humidity inside and outside of the building during thirty consecutive days in summer season. This monitoring was perfomed with the use of a meteorological station La Crosse and a thermo-hygrometer with datalogger, ONSET brand, model HOBO U10, in the external part of the building. In the interior part, the monitoring was conducted with other nineteen thermo-hygrometers, positioned in several spaces inside the library. The data measured was treated in Microsoft Excel 2010 software. As a result of the study it was noticed a low thermal performance of the building, which is provided mainly by both the low performance of the roof, composed by fibrocement tiles and plaster ceiling, and the east and west facades, where big glass windows are placed, without protection against solar radiation.

Keywords: Thermal Performance, Thermal Comfort, envelope

\section{INTRODUÇÃO}

Em 2001, o Brasil vivenciou a maior crise do setor energético de sua história. A partir de então, diversas estratégias foram adotadas, desde a ampliação e diversificação do sistema de geração de energia, até programas de redução do consumo que envolveram os usuários finais. No início de 2014, após um período atípico de estiagem, a possibilidade de racionamento de água e energia tornou-se novamente um risco eminente, voltando a ser foco de debates nas esferas social, política e econômica.

De acordo com o relatório final do balanço energético nacional, ano base 2012, (EPE, 2013), os setores residencial, comercial e público corresponderam a 47,6\% do consumo de eletricidade no país. Dos quais, grande parte é destinada ao condicionamento de ar e a iluminação artificial. Nesse sentido, observa-se o potencial de contribuição das edificações na redução da demanda por energia elétrica.

É importante perceber que o desempenho térmico e o aproveitamento da iluminação natural são determinados ainda na fase de projeto, quando são definidas a orientação, a forma e a envoltória da edificação. Por isso, a adoção de princípios bioclimáticos durante a fase de projeto possibilita o alcance de altos níveis de eficiência energética. Por outro lado, os edifícios existentes, também podem ter seus desempenhos melhorados ao passar por processos de retrofit $^{1}$ que busquem adequar as construções aos climas nos quais estão inseridos.

Buscando a eficiência energética nas edificações, foram regulamentados nos últimos anos diversos mecanismos de orientação, avaliação e controle, tais como a Norma Brasileira de Desempenho Térmico das Edificações NBR15220 (ABNT, 2005), o Regulamento Técnico da Qualidade de eficiência Energética de Edificações Comerciais, de Serviços e Públicos (RTQ-C, 2010) e Residenciais (RTQ-R, 2012), além da Norma Brasileira de Desempenho de Edificações Habitacionais, NBR 15575 (ABNT, 2013) que determina

\footnotetext{
${ }^{1}$ Retrofit: processo de adequação do edifício as necessidades atuais.
} 
parâmetros relativos a segurança, habitabilidade e sustentabilidade das edificações, destacando-se neste contexto, o desempenho térmico e lumínico das edificações.

Essas ferramentas, apesar de tratarem especialmente da concepção de novos edifícios, podem, e devem, ser utilizadas como diretrizes para avaliação dos edifícios existentes, fornecendo parâmetros para as adequações necessárias. Nesse sentido, foi realizado o monitoramento térmico da biblioteca Nilo Peçanha, localizada no Instituto Federal de Educação, Ciência e Tecnologia da Paraíba, João Pessoa/PB, com o objetivo de avaliar o comportamento térmico do edifício, considerando o desempenho da sua envoltória e a sua capacidade de proporcionar a sensação de conforto térmico aos seus usuários.

\section{MATERIAIS E MÉTODOS}

A biblioteca Nilo Peçanha possui uma área total aproximada de 767,50 $\mathrm{m}^{2}$, dividida em dois pavimentos. O pavimento térreo é composto por 14 ambientes, destinados a atividades administrativas e atendimento ao público, enquanto o pavimento superior configura-se em um vão único, abrigando as estantes de livros e as áreas de estudo. $\mathrm{O}$ edifício é completamente condicionado artificialmente por aparelhos do tipo Split e não há a possibilidade de abertura das janelas. A coberta, com área de 552,00 $\mathrm{m}^{2}$ é composta por telha fibrocimento e forro de gesso, enquanto as paredes são compostas por $376 \mathrm{~m}^{2}$ de alvenaria revestida por cerâmica de cores escuras e $160 \mathrm{~m}^{2}$ de esquadrias de vidro comum de $3 \mathrm{~mm}$ com alumínio anodizado, cor preta.

O monitoramento térmico da biblioteca foi realizado no período de 26/02/2013 a 10/04/2013, com auxílio de 20 termohigrômetros com datalogger, marca: ONSET, modelo: HOBO U10 e uma estação meteorológica, marca: La Crosse. Essa estação foi instalada na área externa da biblioteca juntamente com um dos termohigrômetros Hobo. No interior foram instalados os demais termohigrômetros, sendo 15 desses instalados no pavimento térreo e 4 no pavimento superior, visualizados na Figura 01 . Os equipamentos registraram a temperatura e a umidade relativa do ar a cada hora, ininterrupta e simultaneamente.

\section{Figura 01: Planta baixa da Biblioteca Nilo Peçanha com a localização dos equipamentos} registradores de temperatura e umidade.
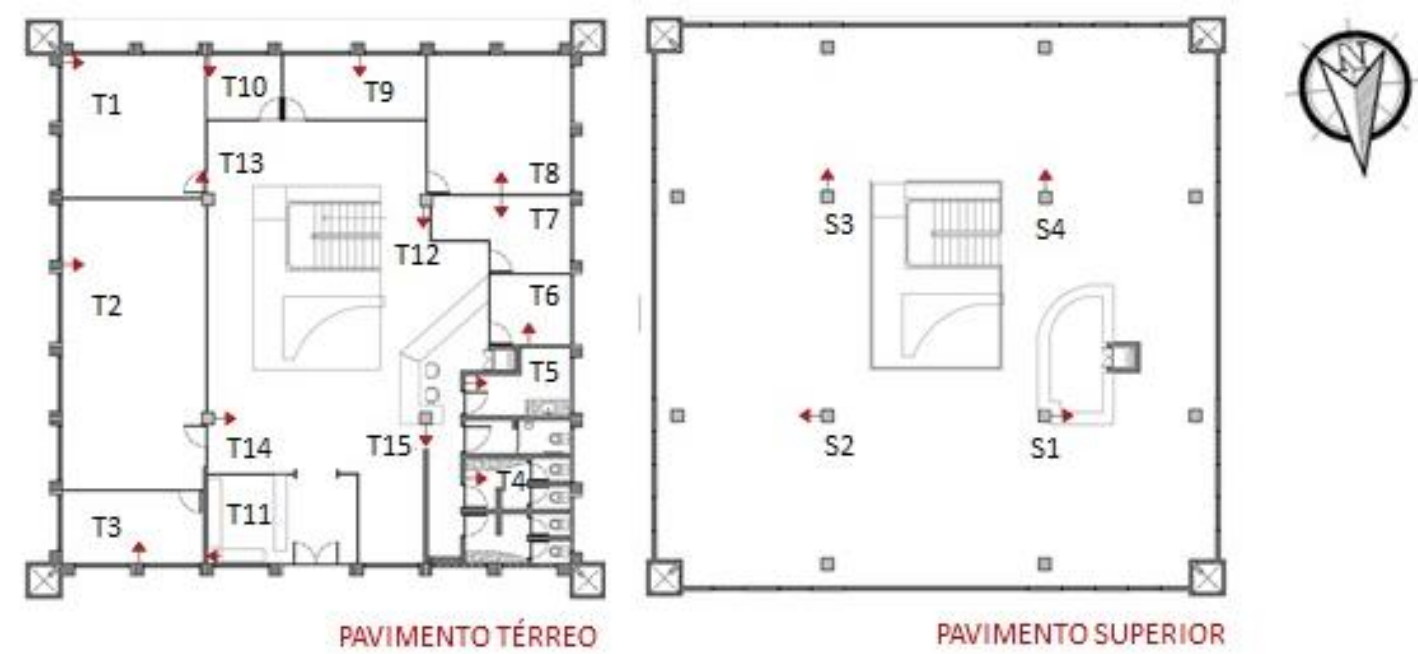

Ao término das medições os dados foram baixados para um computador e tratados no software Microsoft Excel, em que foram feitos os cálculos de média, máximo e mínimo e a elaboração de gráficos de comparação dos dados. 
Os dados foram estratificados em dois grupos contendo os dados medidos durante os domingos, quando a biblioteca não estava em funcionamento e, portanto, com o sistema de condicionamento do ar desligado. Essa condição possibilitou uma análise mais precisa do desempenho da edificação, uma vez que os dados não sofreram influência da climatização artificial.

No primeiro grupo, a avaliação de desempenho da edificação considerou os dados medidos em cada ponto às $7 \mathrm{~h}, 10 \mathrm{~h}, 13 \mathrm{~h}, 16 \mathrm{~h}$ e $19 \mathrm{~h}$, possibilitando a visualização do processo de resfriamento e aquecimento da edificação. O tratamento visual dos dados foi realizado a partir da atribuição de uma escala de cores ao identificar as temperaturas mais baixas com a cor verde e as mais altas com a cor vermelha.

No segundo grupo, também correspondente aos domingos, os dados foram agrupados por períodos, manhã (8:00 às 12:00), tarde (13:00 às 17:00) e noite (18:00 às 22:00), considerou-se apenas os dados medidos nos pontos T1 e T15 (térreo) e S1 (pavimento superior), situados nos ambientes de maior permanência de usuários, respectivamente, sala de informática, balcão de empréstimo e reservas e salão de leitura. Também avaliouse as os dados medidos no exterior da edificação para verificar, de acordo com as condições do microclima local, quais estratégias de projeto deveriam ter sido adotadas na edificação da biblioteca, comparando-as com as de fato adotadas.

\section{RESULTADOS E DISCUSSÃO}

\subsection{ANÁLISE DO DESEMPENHO TÉRMICO DO EDIFÍCIO}

A avaliação do desempenho térmico da edificação foi realizada tomando como referência os dados medidos no dia 31/03/2013 (Figura 02), dia de domingo escolhido entre os demais observados por ter tido maior $\left(33^{\circ} \mathrm{C}\right.$, às $\left.13 \mathrm{~h}\right)$ e a menor $\left(25^{\circ} \mathrm{C}\right.$, às $\left.5 \mathrm{~h}\right)$ temperaturas registradas no exterior da edificação no período da pesquisa e, portanto, a maior amplitude térmica registrada, atingindo $8^{\circ} \mathrm{C}$.

Figura 02: Comportamento térmico da área externa durante os domingos monitorados.

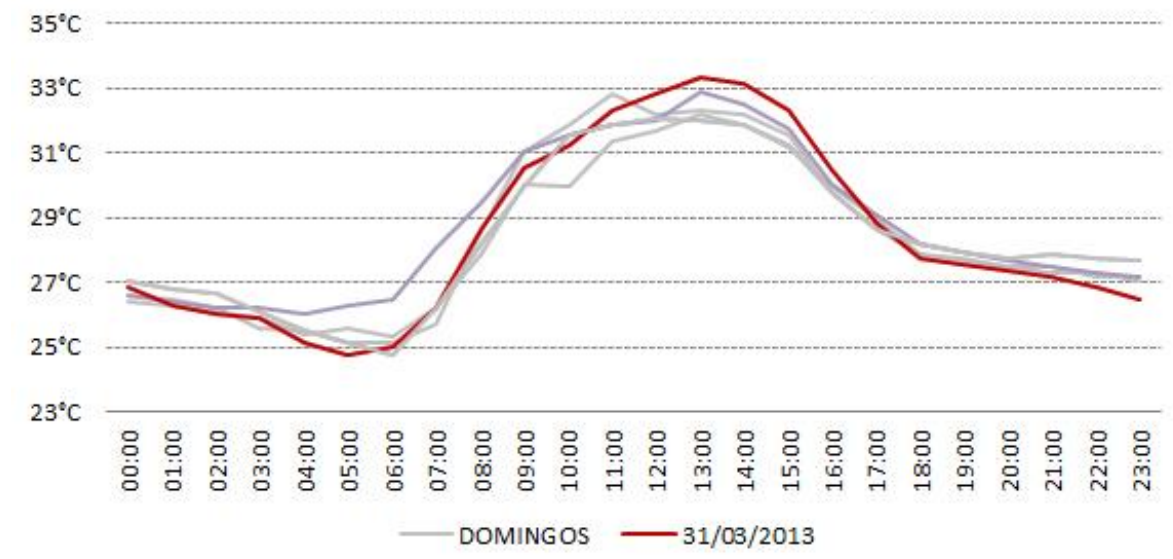

No interior do edifício, como não há ventilação natural, percebeu-se às $7 \mathrm{~h}$ o efeito da inércia térmica da edificação, uma vez que a temperatura interna permaneceu, em todos os pontos, superior à temperatura externa (Tabela 01). A temperatura no interior esteve mais elevada nos pontos $\mathrm{T} 5 \mathrm{e} \mathrm{T} 6$, provavelmente devido à carga térmica produzida por equipamentos instalados nos ambientes referentes a esses pontos (copa e depósito). 
Tabela 01: Variação da temperatura do ar no interior da edificação durante o período de funcionamento, com graduação de cores, sendo as células verdes referente às temperaturas mais baixas e as vermelhos às temperaturas mais elevadas.

\begin{tabular}{|c|c|c|c|c|c|c|c|c|c|c|c|c|c|c|c|c|c|c|c|}
\hline & \multicolumn{15}{|c|}{ PAVIMENTO TÉRREO } & \multicolumn{4}{|c|}{ PAVIMENTO SUPERIOR } \\
\hline & T1 & $\mathrm{T} 2$ & T3 & T4 & T5 & T6 & T7 & T8 & T9 & T10 & T11 & T12 & T13 & T14 & T15 & S1 & S2 & S3 & S4 \\
\hline Hora & $\left({ }^{\circ} \mathrm{C}\right)$ & $\left({ }^{\circ} \mathrm{C}\right)$ & $\left({ }^{\circ} \mathrm{C}\right)$ & $\left({ }^{\circ} \mathrm{C}\right)$ & $\left({ }^{\circ} \mathrm{C}\right)$ & $\left({ }^{\circ} \mathrm{C}\right)$ & $\left({ }^{\circ} \mathrm{C}\right)$ & $\left({ }^{\circ} \mathrm{C}\right)$ & $\left({ }^{\circ} \mathrm{C}\right)$ & $\left({ }^{\circ} \mathrm{C}\right)$ & $\left({ }^{\circ} \mathrm{C}\right)$ & $\left({ }^{\circ} \mathrm{C}\right)$ & $\left({ }^{\circ} \mathrm{C}\right)$ & $\left({ }^{\circ} \mathrm{C}\right)$ & $\left({ }^{\circ} \mathrm{C}\right)$ & $\left({ }^{\circ} \mathrm{C}\right)$ & $\left({ }^{\circ} \mathrm{C}\right)$ & $\left({ }^{\circ} \mathrm{C}\right)$ & $\left({ }^{\circ} \mathrm{C}\right)$ \\
\hline $7: 00$ & 29,6 & 29,3 & 29,3 & 29,1 & 30,0 & 29,8 & 29,1 & 29,0 & 28,8 & 29,1 & 29,0 & 29,0 & 29,2 & 28,9 & 28,9 & 29,3 & 29,5 & 29,4 & 29,3 \\
\hline $0: 00$ & 1,1 & 29,9 & 30,4 & 29,3 & 29,7 & 29,9 & 29,5 & 29,7 & 29,6 & 29,9 & 30,3 & 29,3 & 30,1 & 29,4 & 29,2 & 32,1 & 32,5 & 32,4 & 32,2 \\
\hline $13: 00$ & 31,4 & 30,2 & 30,8 & 29,7 & 29,9 & 30,2 & 30,0 & 30,4 & 30,2 & 30,4 & 30,6 & 29,6 & 30,3 & 29,7 & 29,7 & 34,1 & 34,8 & 34,8 & 34,2 \\
\hline $16: 00$ & 31,6 & 30,5 & 30,7 & 30,9 & 33,1 & 32,7 & 33,5 & 34,3 & 30,6 & 30,6 & 30,6 & 30,2 & 30,4 & 29,8 & 29,9 & 34,6 & 34,3 & 34,5 & 34,0 \\
\hline 19:00 & 31,1 & 30,2 & 30,4 & 30,2 & 31,4 & 31,1 & 30,5 & 31,1 & 30,3 & 30,3 & 30,0 & 29,7 & 29,9 & 29,6 & 29,6 & 32,4 & 32,5 & 32,5 & 32,2 \\
\hline
\end{tabular}

Às $10 \mathrm{~h}$, enquanto no exterior a temperatura se elevou em $5^{\circ} \mathrm{C}$, no interior a variação da temperatura atingiu $2^{\circ} \mathrm{C}$ no pavimento superior, bem mais significativa do que no térreo, onde a variação chegou a, nó máximo, $1,3^{\circ} \mathrm{C}$ no ponto $\mathrm{T} 11$, localizado no setor de guardavolumes da biblioteca. No pavimento superior a variação se explica, principalmente pela energia térmica absorvida pelas aberturas sem proteção solar externa da fachada leste e pela cobertura composta por telha de fibrocimento e forro de gesso, que combinados, proporcionam pouca resistência térmica.

A variação identificada às $10 \mathrm{~h}$ foi mais intensa nos horários subsequentes, especialmente às $13 \mathrm{~h}$, quando a temperatura externa atingiu o valor máximo (Tabela 01 ). O pavimento superior foi o ambiente que se manteve mais aquecido, por receber uma maior quantidade de calor oriunda, principalmente da cobertura e das fachadas leste e oeste, que possuem janelas em vidro. A cobertura possui absortância $\alpha=75 \%$ e transmitância térmica $U=1,94$ $\mathrm{W} /\left(\mathrm{m}^{2} . \mathrm{K}\right)$, superiores aos exigidos pelo RTQ-C. As janelas, nas quatro fachadas, não possuem elementos de proteção solar externo, apenas persianas internas horizontais na cor cinza claro.

À tarde, devido às janelas de vidro situadas na fachada oeste, os ambientes T5, T6, T7 e T8 atingiram as maiores temperaturas no pavimento térreo, atingindo valores semelhantes aos do pavimento superior (Tabela 01).

À noite esses ambientes permaneceram mais quentes do que os demais. Os pontos mais quentes foram os que tiveram a maior perda de calor entre $16 \mathrm{~h}$ e $19 \mathrm{~h}$. Mas a perda foi maior no térreo, atingindo $3,1^{\circ} \mathrm{C}$ no ponto $\mathrm{T} 7$ e $3,2^{\circ} \mathrm{C}$ no $\mathrm{T} 8$, sendo essa perda mais acentuada devida ao tempo menor de exposição das janelas desses ambientes à radiação solar direta, em relação ao pavimento superior, proporcionada pelo sombreamento provocado pelas edificações do entorno.

As temperaturas internas estiveram superiores às externas no pavimento superior, das $10 \mathrm{~h}$ às $19 \mathrm{~h}$, e nos pontos T5, T6, T7 e T8, das $16 \mathrm{~h}$ às $19 \mathrm{~h}$, atingindo $4^{\circ} \mathrm{C}$ às $19 \mathrm{~h}$, confirmando a inércia térmica da edificação e indicando a grande quantidade de calor a ser reduzida pelo sistema de condicionamento do ar, uma vez que a temperatura interna chegou a superar os $34^{\circ} \mathrm{C}$ nos ambientes mais quentes, quando o nível de conforto seria de, no máximo, $28^{\circ} \mathrm{C}$. 


\subsection{ANÁLISE DE CONFORTO TÉRMICO DE ACORDO COM A CARTA BIOCLIMÁTICA DE GIVONI}

Inicialmente analisou-se as condições do microclima local, onde está situada a biblioteca para avaliar se as características físicas da edificação estão compatíveis com as estratégias de projeto sugeridas na carta bioclimática de Givoni.

Percebe-se na Figura 03, que na maior parte do tempo, nos três turnos, as condições ambientais (temperatura e umidade) estiveram fora da zona de conforto. Para essas condições, a carta bioclimática indica principalmente, como estratégia, a necessidade de se melhorar as condições de ventilação para se promover o resfriamento do ambiente.

Figura 03: Distribuição dos pontos higrotérmicos, referente ao ponto externo, sob a carta bioclimática de Givoni com os percentuais de ocorrência para cada zona.

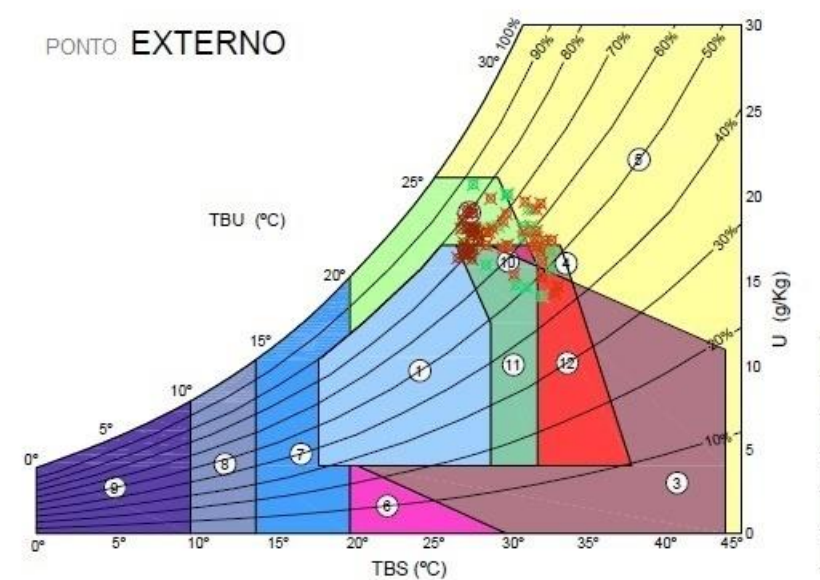

\begin{tabular}{|l|c|c|c|r|r|r|r|r|}
\hline \multicolumn{7}{|c|}{ PONTO EXTERNO } \\
\hline & Z1 & Z2 & Z3 & Z4 & Z5 & Z10 & Z11 & Z12 \\
\hline MANHÃ & $0 \%$ & $24 \%$ & $0 \%$ & $16 \%$ & $44 \%$ & $0 \%$ & $12 \%$ & $4 \%$ \\
\hline TARDE & $0 \%$ & $28 \%$ & $0 \%$ & $16 \%$ & $32 \%$ & $8 \%$ & $4 \%$ & $12 \%$ \\
\hline NOITE & $4 \%$ & $64 \%$ & $0 \%$ & $0 \%$ & $0 \%$ & $0 \%$ & $32 \%$ & $0 \%$ \\
\hline TOTAL & $\mathbf{1} \%$ & $\mathbf{3 9} \%$ & $\mathbf{0} \%$ & $\mathbf{1 1} \%$ & $\mathbf{2 5} \%$ & $\mathbf{3} \%$ & $\mathbf{1 6 \%}$ & $\mathbf{5 \%}$ \\
\hline
\end{tabular}

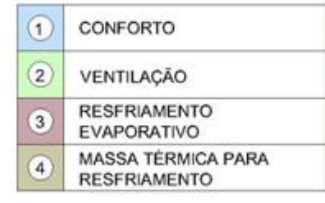

\begin{tabular}{|l|l|}
\hline 5 & AR CONDICIONADO \\
\hline 6 & UMIDIFICAÇĀO \\
\hline 7 & $\begin{array}{l}\text { MASSA TÉRMICA } \\
\text { AQUECIMENTO }\end{array}$ \\
\hline 8 & $\begin{array}{l}\text { AQUECIMENTO SOLAR } \\
\text { PASSIVO }\end{array}$ \\
\hline
\end{tabular}

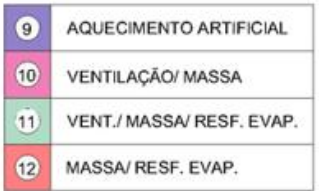

Os valores das temperaturas medidas em cada um desses ambientes foram lançados na carta bioclimática de Givoni, adaptada para João Pessoa. Nesta carta (Figura 03, 04, 05 e 06) os pontos de cor verde referem-se aos dados coletados no período da manhã ( $8 \mathrm{~h}$ às $12 \mathrm{~h}$ ); os pontos laranjas, aos dados obtidos à tarde (13h às $17 \mathrm{~h})$; os pontos marrons referem-se às temperaturas medidas à noite ( $18 \mathrm{~h}$ às $22 \mathrm{~h})$.

Os dados obtidos no ambiente externo são utilizados como referência conceitual de um edifício naturalmente ventilado em que as condições higrotérmicas internas assemelhamse as externas. Neste sentido, observa-se na figura 03 que apenas $1 \%$ dos dados encontram-se na zona de conforto, enquanto $75 \%$ requerem estratégias passivas de condicionamento do ar e $25 \%$ exigem o uso do condicionamento de ar artificial. Em geral, as temperaturas foram superiores a $25^{\circ} \mathrm{C}$ acompanhadas por alta umidade do ar, indicando principalmente a necessidade do uso da ventilação para proporcionar a sensação de conforto.

No pavimento inferior, pontos $\mathrm{T} 1 \mathrm{e} \mathrm{T} 15$, o agrupamento dos pontos referentes aos dados higrotérmicos apresentam uma forma compacta de distribuição, demonstrando semelhança nas condições ambientais durante os diferentes turnos, observar figuras $04 \mathrm{e}$ 05. No ponto $\mathrm{T} 1$, houve integralmente a necessidade de ventilação, sendo necessária também a utilização de massa térmica para resfriamento em $73 \%$ do tempo. A maior 
concentração ocorreu na zona 11, que exige além das estratégias mencionadas a utilização de resfriamento evaporativo.

Figura 04: Distribuição dos pontos higrotérmicos, referente ao ponto T1, sob a carta bioclimática de Givoni com os percentuais de ocorrência para cada zona.
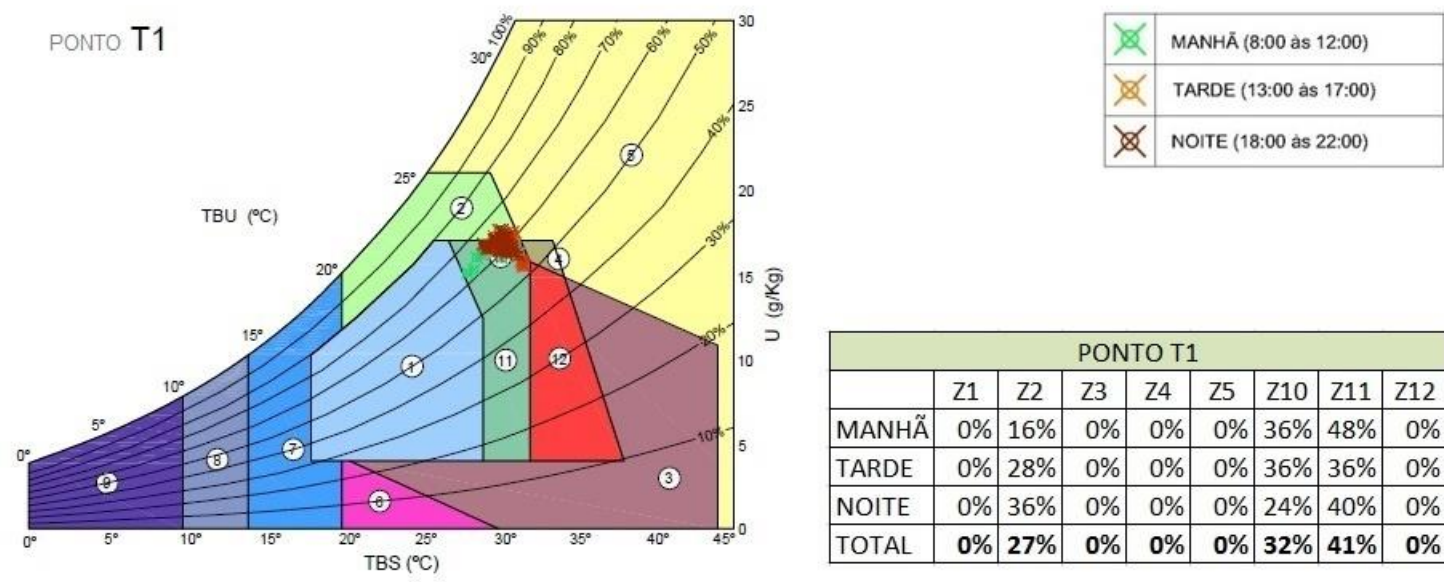

O ponto T15 registrou condições ambientais mais amenas em relação ao ponto T1, havendo apenas a necessidade de implantação de estratégias relacionadas a ventilação e a massa térmica. Essa diferença deve ser atribuída à influência da localização do ambiente monitorado pelo HOBO T1, pois este, possui duas fachadas, sul e oeste, além de abrigar maior concentração de usuários e diversos computadores, por se tratar de uma sala de informática.

Observa-se também, que durante o período matutino, os dados obtidos estavam mais próximos à zona de conforto em ambos os casos, demonstrando assim, a influência do atraso térmico em seu comportamento térmico.

Figura 05: Distribuição dos pontos higrotérmicos, referente ao ponto T15, sob a carta bioclimática de Givoni com os percentuais de ocorrência para cada zona.
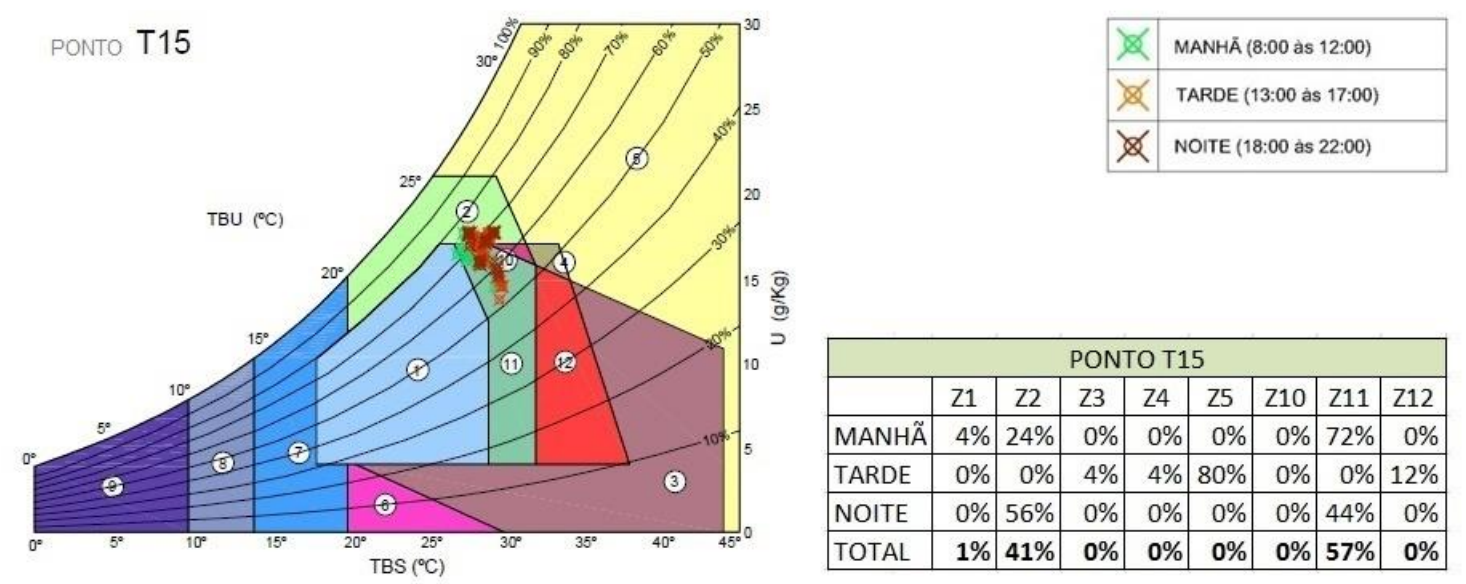

No pavimento superior, observar figura 06, ocorreu uma distribuição mais espraiada dos conjuntos de dados analisados, observou-se a necessidade de uma grande variedade de estratégias para o alcance do conforto térmico (zonas 2, 3, 4, 5, 10, 11 e 12). Em nenhum momento observou-se dados inseridos na zona de conforto térmico, enquanto $43 \%$ situam-se na zona 5 , referente à necessidade de implantação de condicionamento do ar artificial. 
Percebe-se a total inadequação do ambiente térmico proporcionado aos usuários da biblioteca, pois apesar de se tratar de um espaço destinado às atividades sedentárias, é sabido, que a atividade mental é bastante prejudicada pela condição de stress térmico por calor ao qual se está submetendo os usuários.

Figura 06: Distribuição dos pontos higrotérmicos, referente ao ponto S1, sob a carta bioclimática de Givoni com os percentuais de ocorrência para cada zona.

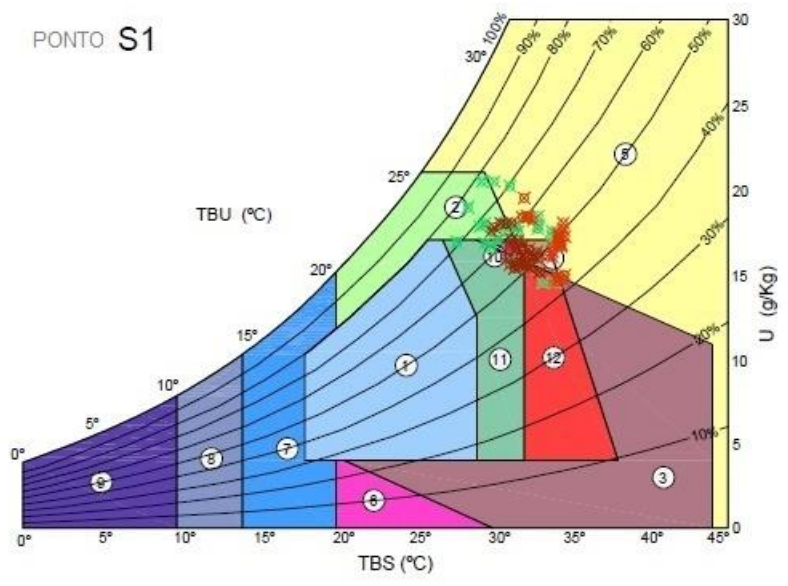

\begin{tabular}{|l|c|r|r|r|r|r|r|r|}
\hline \multicolumn{10}{|c|}{ PONTO S1 } \\
\hline & Z1 & Z2 & Z3 & Z4 & Z5 & Z10 & Z11 & Z12 \\
\hline MANHÃ & $0 \%$ & $28 \%$ & $0 \%$ & $0 \%$ & $44 \%$ & $4 \%$ & $12 \%$ & $12 \%$ \\
\hline TARDE & $0 \%$ & $0 \%$ & $4 \%$ & $4 \%$ & $80 \%$ & $0 \%$ & $0 \%$ & $12 \%$ \\
\hline NOITE & $0 \%$ & $16 \%$ & $0 \%$ & $28 \%$ & $4 \%$ & $16 \%$ & $24 \%$ & $12 \%$ \\
\hline TOTAL & $\mathbf{0} \%$ & $\mathbf{1 5 \%}$ & $\mathbf{1} \%$ & $\mathbf{1 1} \%$ & $\mathbf{4 3} \%$ & $\mathbf{7 \%}$ & $\mathbf{1 2 \%}$ & $\mathbf{1 2 \%}$ \\
\hline
\end{tabular}

Dessa forma observou-se a ineficiência da edificação em proporcionar conforto térmico aos usuários nas regiões de maior fluxo durante todos os períodos. Observa-se assim, a necessidade de melhoria do desempenho térmico do edifício através de intervenções em sua envoltória, tais como implantação de elementos de proteção solar nas aberturas do pavimento superior, assim como, a necessidade de tratamento na coberta para obter menor absortância e transmitância térmica, ratificando os resultados da primeira análise.

\section{CONSIDERAÇÕES FINAIS}

A avaliação de desempenho térmico dos edifícios já existentes é fundamental para a verificação do seu nível de conforto térmico e de consumo energético. Nesta pesquisa, foram realizadas duas análises para a compreensão do comportamento térmico da biblioteca Nilo Peçanha, a primeira avaliou o desempenho geral do edifício sem o uso de aparelhos condicionadores de ar, e a segunda, analisou a capacidade do edifício em propiciar conforto térmico aos seus usuários. Constatou-se a ineficiência da edificação em proporcionar conforto, devido ao fraco desempenho da sua envoltória.

Destaca-se dois principais elementos para o fraco desempenho: a inadequação da coberta de alta absortância e transmitância térmica, assim como, a ausência de proteção solar externa nas aberturas do pavimento superior. Indica-se, para a sequência dessa pesquisa, a simulação e avaliação das recomendações de adequação sugeridas, com o propósito de fornecer subsídios para auxiliar a concepção do projeto de adequação do edifício.

\section{REFERÊNCIAS}

ASSOCIAÇÃO BRASILEIRA DE NORMAS TÉCNICAS (ABNT). NBR-15220: Desempenho Térmico de Edificações. Rio de Janeiro, 2005.

ASSOCIAÇÃO BRASILEIRA DE NORMAS TÉCNICAS (ABNT). NBR-15575: Edificações Habitacionais - Desempenho. Rio de Janeiro, 2013. 
EPE. Balanço Energético Brasileiro: Ano Base 2012. EPE. Rio de Janeiro, p. 288. 2013.

GIVONI, Baruch. Climate Considerations in Building and Urban Design. New York: Van Nostrand Reinhold, 1998.

INSTITUTO NACIONAL DE METROLOGIA, QUALIDADE E TECNOLOGIA. Regulamento Técnico da Qualidade do Nível de Eficiência Energética de Edifícios Comerciais, de Serviços e Públicos. RTQ-C. Portaria n. ${ }^{\circ} 372$, de 17 de Setembro de 2010. INMETRO, 2010.

INSTITUTO NACIONAL DE METROLOGIA, QUALIDADE E TECNOLOGIA. Regulamento Técnico de Qualidade para o Nível de Eficiência Energética de Edificações Residenciais. RTQ-R. Portaria n. ${ }^{\circ} 18$, de 16 de Janeiro de 2012. INMETRO, 2012. 